\title{
LA CULTURA DE LA ALIMENTACIÓN. PATRIMONIO GASTRONÓMICO DE LAS SOCIEDADES EN PROCESO DE CAMBIO Y SU DIFUSIÓN
}

\author{
José Aniorte Pérez a , Borja Guilló Soler b, Rafael Martínez García c, Isabel Picó \\ Ledesma d, Marian Tristán Richarte ${ }^{\mathrm{e}}$ \\ a aniorte.gestion@gmail.com, binfo@museopusol.com, c fundacion@museopusol.com \\ d03015208@gva.es, ${ }^{e}$ comunicacion@museopusol.com
}

\begin{abstract}
This communication approaches those cultural manifestations that, around food, are shown in the School Museum of Puçol (Elche). It is divided into four sections, related to the essential functions of any museum: conservation, research and dissemination, as they are developed in this museum, whose spaces reflect, in a transversal way, food, understood in its various meanings. In the first place, the traditional agricultural processes of the Camp d'Elx -and of the Mediterranean environment- are described, associated with cereal, vine and olive crops. Second, it describes the preparation and consumption of food at home from these products, recipes and processes compiled thanks to the recovery of oral memory. Thirdly, it talks about catering establishments and the buying and selling of food-related products in markets and retail stores. Finally, it addresses the dissemination that the museum carries out of the aforementioned, that is, the dissemination of social processes and practices related to food, understood both in the formal educational context and in the museum's own dynamics.
\end{abstract}

Keywords: museum, heritage, food, consumption, Mediterranean, agriculture, education.

Resumen: La presente comunicación se aproxima a aquellas manifestaciones culturales que, en torno a la alimentación, se muestran en el Museo Escolar de Puçol (Elche). Se divide en cuatro apartados, relacionados con las funciones esenciales de todo museo: conservación, investigación y difusión, tal y como se desarrollan en este, cuyos espacios reflejan, de manera transversal, la alimentación, entendida en sus varias acepciones. En primer lugar, se explican los procesos agrícolas tradicionales del Camp d'Elx -y del entorno Mediterráneo-, asociados a los cultivos del cereal, de la vid y del olivo. En segundo lugar, se describe la elaboración y el consumo de alimentos en el ámbito doméstico a partir de estos productos, recetas y procesos compilados gracias a la recuperación de la memoria oral. En tercer lugar, se habla de los establecimientos de restauración y de la compra-venta de los productos relacionados con la alimentación en mercados y comercios minoristas. Por último, se aborda la difusión que desde el museo se lleva a cabo de lo anteriormente descrito, es decir, la divulgación de los procesos y prácticas sociales relacionados con la alimentación, entendida tanto en el contexto educativo formal como en la dinámica propia del museo.

Palabras clave: museo, patrimonio, alimentación, consumo, Mediterráneo, agricultura, educación.

Citar como: Aniorte Pérez, J., Guilló Soler, B., Martínez García, R., Picó Ledesma, I., Tristán Richarte, M. (2022). "La cultura de la alimentación. Patrimonio gastronómico de las sociedades en proceso de cambio y su difusión". En: Actas del III Congreso Internacional sobre Patrimonio Alimentario y Museos. 25-26 noviembre, 2021, Valencia, España. pp. 231-246. https://doi.org/10.4995/EGEM2021.2021.13332 


\section{Introducción: el Museo Escolar de Puçol}

El Museo Escolar de Puçol se encuentra en la pedanía ilicitana homónima y conserva fondos etnográficos de carácter material e inmaterial relacionados con la vida considerada tradicional de su entorno ${ }^{1}$. Desde sus inicios, este museo, surgido en la década de los setenta como resultado de un proyecto educativo que trascendió las aulas del colegio de esta partida rural, caminó junto a una comunidad que ya entonces lo hizo suyo y lo ha venido arropando en todas aquellas iniciativas que ha liderado.

A caballo entre las décadas de los sesenta y setenta, el profesor García Fontanet -joven maestro recién destinado al colegio de Puçol- puso en marcha una experiencia pedagógica que contextualizaría la modesta escuela en su medio, utilizando la cultura local como recurso didáctico (Martínez et. al., 2019). Fueron unos años de radicales transformaciones en la sociedad y en la economía españolas, cambios que también afectaron al Campo de Elche. La masiva urbanización y la pérdida progresiva de conocimientos relacionados con el mundo agrario, entre otros, informaron una coyuntura de crisis percibida con preocupación por parte de los/as docentes destinados/as en los pequeños centros unitarios dispersos por el extenso término ilicitano, que se dispusieron a "combatir" esa suerte de desarraigo instalada en el seno de la comunidad rural (García y Pérez, s.f).

En este contexto, la incorporación al aula de materias y conocimientos relacionados con el mundo natural y cultural del entorno, vinculó estrechamente a la escuela con la sociedad rural. Desde principios de la década de los setenta, el alumnado comenzó a estudiar las faenas agrícolas y otros oficios en vías de desaparición, recopilando la memoria oral de las personas mayores del Campo de Elche, iniciando, así, su estudio etnográfico. Con el objetivo de recuperar y poner en valor el patrimonio de la zona, comenzaron a realizarse donaciones de objetos a la escuela, principalmente de antiguas herramientas y menaje, que fueron restaurados, estudiados y expuestos en el aula por los/as escolares. De esta forma, se consiguió involucrar a la comunidad en el proceso de puesta en valor de su cultura, dando lugar a una relación profunda y multidireccional de la que ambas, colegio y pedanía, se beneficiaron.

Consecuencia directa de la experiencia educativa puesta en marcha en Puçol -que consiguió aplicarse en escuelas de pedanías vecinas-, es el Museo Escolar (de Puçol), fundado en 1979 y reconocido en 1992. Entre otros premios y distinciones, en 2009, el proyecto educativo del museo sería incluido por la UNESCO en el Registro de Buenas Prácticas de Salvaguarda del Patrimonio Cultural Inmaterial².

\footnotetext{
1 Creemos oportuno establecer una precisión en cuanto al concepto de "tradición" en su acepción etnográfica, concepto que a menudo se emplea, quizás, indiscriminadamente. Probablemente, la memoria del campo definido como "tradicional", aquella que se decide conservar en el colegio de Puçol a partir del último tercio del siglo XX, un campo por entonces poblado de acequias y cultivos hortícolas, en buena medida era resultado de las transformaciones sobrevenidas a comienzos de la pasada centuria, cuando la instalación de motores eléctricos en el territorio hizo posible elevar aguas procedentes del tramo final del Segura y de algunos de sus azarbes. Por tanto, aunque continuó utilizándose un utillaje arcaico, habida cuenta de que el Camp d'Elx -como el resto del territorio español- no se mecanizaría hasta la década de los sesenta, el hecho de elevar agua merced a motores y las consecuencias derivadas de ello no permite hablar de sociedades tradicionales sensu stricto.

2 https://ich.unesco.org/es/BSP/-00306 (UNESCO, Organización de las naciones Unidas para la Educación, la Ciencia y la Cultura).
} 


\section{Objetivos}

Los objetivos que se plantean en la presente comunicación son los siguientes:

1. Dar a conocer el Museo Escolar de Puçol, incluido por la UNESCO en el Registro de Buenas Prácticas de Salvaguarda del Patrimonio Cultural Inmaterial (2009).

2. Describir el patrimonio material e inmaterial vinculado a la gastronomía existente en el museo.

3. Explicar la difusión que se realiza de este patrimonio en el museo.

\section{Desarrollo de la innovación}

\subsection{Cultivos tradicionales del Camp d'Elx}

El Museo Escolar de Puçol exhibe la trilogía de cultivos mediterránea, cuya presencia en nuestras tierras fue mayoritaria hasta el siglo XX (Lacarra, Sánchez y Jarque, 1997). A partir de las primeras décadas de la pasada centuria, cuando fue posible regar el Camp d'Elx, como se ha indicado, con aguas elevadas del Bajo Segura, comenzaron a extenderse otros cultivos que, en adelante, compartirían "mesa y mantel" con las históricas producciones ilicitanas, que iniciaron su retroceso ${ }^{3}$.

Gozálvez, (1977: 115) en su conocida obra sobre la geografía agraria de la comarca, sostiene que "[la] implantación [de los cultivos hortícolas] en superficies importantes se inicia en los años veinte de nuestro siglo, posibilitados por Riegos de Levante [...]". Tanto la regresión experimentada por los cereales como su sustitución por cultivos hortícolas se pone de manifiesto cuando, más adelante, este autor afırma que "[el trigo y la cebada] son cultivos en regresión [y que] suelen aprovechar los rastrojos de pimientos y melones" (Gozálvez, 1977: 120), producciones hortícolas que, junto a otras, alcanzaron un importante crecimiento a lo largo del novecientos.

Con carácter general, la exposición del museo -resultado de un trabajo de investigación dilatado en el tiempo, en el que el concurso de la comunidad, a través del colegio, resultó decisivo- obedece a diferentes formas de presentación (Hernández, 1994). En cuanto a los cultivos que nos ocupan, aunque los aperos y el resto de objetos se muestran utilizando un criterio tipológico que atiende a aspectos formales, este se combina con otro funcionalista al incorporar murales y fotografías en los que se representa el medio original y escenas con la función o el manipulado de aquellos. En general, se puede afirmar que la exposición relacionada con estos cultivos se corresponde con un planteamiento didáctico -sin excluir la emotividad o el entretenimiento-, aquel que busca instruir y educar, tal y como se explicita en el proyecto educativo original que dio origen al museo.

En concreto, los procesos del cereal y del olivo -no así el correspondiente al viñedo- se exponen en dos espacios diferenciados, habida cuenta de que el museo dispone de un área de exposición al aire libre estrechamente vinculada con las salas merced a cerramientos transparentes. Así, frente al ciclo del cereal -labranza, siembra, recolección y trilla- que se muestra en el interior del museo, en el exterior se exhibe la era, el pajar y diferentes rulos de piedra y

\footnotetext{
${ }_{3}$ En nuestra zona se constituyeron tres sociedades de riegos: en 1906, Nuevos Riegos El Progreso; en 1917, la Real Compañía de Riegos de Levante; en 1923, Riegos El Porvenir.
} 
herramientas, expuestos y revalorizados en un medio recreado artificialmente. El proceso de obtención del aceite, mostrado en el interior, se complementa con la visión de un olivo en el exterior.

En lo que respecta al cereal, el museo exhibe la preparación del terreno, la labranza, la siembra, la recolección y la trilla, procesos que fueron objeto de un monográfico en su revista ${ }^{4}$. Los aperos para preparar el terreno (tablas, traíllas), labrar (arados, rejas), cosechar (hoces, zoquetas) y trillar (trillos, palas de aventar, recogedores, tamices...) se muestran junto a los yugos (se utilizaban con tracción animal), horcates, frontiles o aguijadas, además de la indumentaria tradicional y diferentes enseres de esparto y mimbre, como capazos, seras o cestas. Una trilladora fabricada por la casa Ajuria (modelo T 110) permanece almacenada en las instalaciones del museo a la espera de una pronta restauración (Figura 1).

En cuanto al viñedo, igualmente en regresión a lo largo del XX, Gozálvez (1977: 129) habla de que "los pissaors y bodegues en desuso existentes en casi todas las casas de labranza construidas antes de 1950 nos hablan de una total elaboración casera del vino, en buena parte para autoconsumo". Así lo atestiguan tanto las pequeñas dimensiones de los lagares conservados como las del resto de enseres e instalaciones empleadas. El museo también conserva

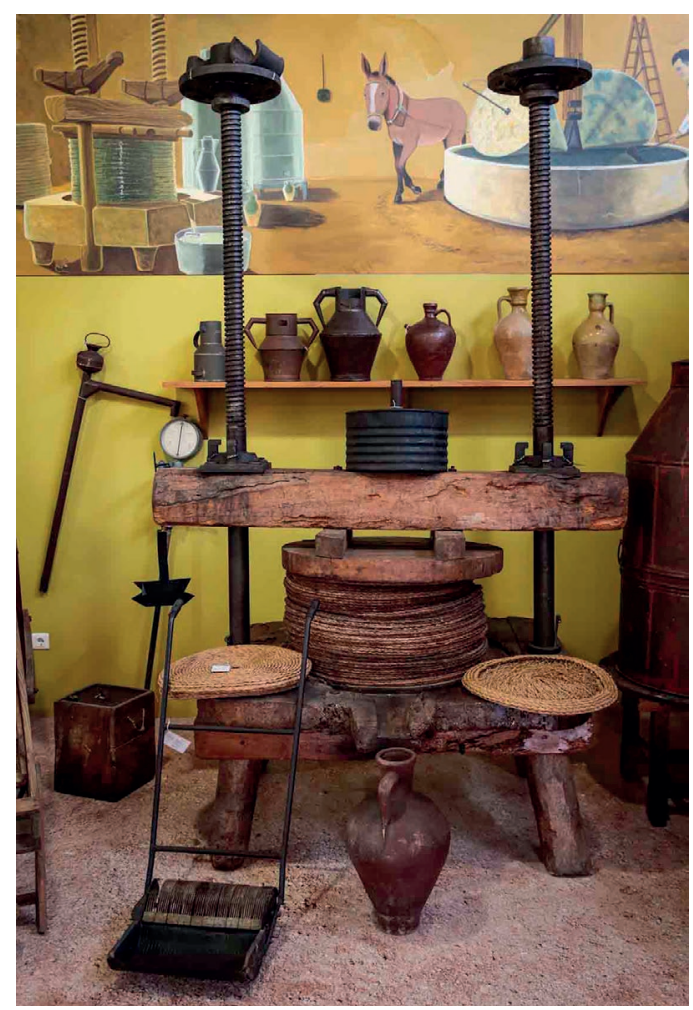

Figura 1. Prensa de aceite expuesta en el Museo Escolar de Puçol. Fuente: Elaboración propia.

\footnotetext{
${ }_{4}$ El Setiet. Boletín Informativo del Museo Escolar Agrícola de Puçol, nº 8, invierno de 1998.
} 
estrujadoras (una de ellas fabricada en Monóvar, Alicante), toneles, cántaros, pellejos o podones, entre otros, herramientas y útiles propios de un cultivo que a lo largo del siglo XX irá reduciendo drásticamente su extensión.

En cuanto a las tareas relacionadas con el cultivo del olivo -tildado como "residual" por Gozálvez (1977: 137) en los setenta y como "secundario" por Brotons (1985: 184), diez años más tarde-, se exhibe un molino de aceite y varias prensas (algunas fabricadas en Alcoy, Alicante), entre las que destaca una de base de piedra y husillos de madera. Zafras, tinajas y medidas, cribas o carretillas ofrecen una visión del utillaje generalmente utilizado en las diferentes faenas asociadas a la recolección de la aceituna y la obtención del aceite.

Producciones como la almendra y la ñora también tienen su reflejo en las salas del museo. Actualmente en retroceso, el almendro, que en los setenta llegó a ocupar miles de hectáreas de extensión en el Campo de Elche, nunca fue abundante en el entorno de Puçol, no obstante lo cual, el museo ha venido recibiendo diversas donaciones de maquinaria asociada a su cultivo. Su expansión se inició en el tránsito de los siglos XIX y XX gracias al bombeo de aguas del Segura, ya mencionado. El museo exhibe una máquina de partir almendra del primer tercio del siglo XX, construida en la fábrica de Silvestre Ivars, de Benissa (Alicante); una separadora de mediados del siglo XX, fabricada por Borrell, en Denia (Alicante) y una descortezadora, probablemente, también de la primera mitad del novecientos.

El pimiento para pimentón, "bola" o ñora también era uno de los cultivos hortícolas más extendidos a comienzos de los setenta, cuando el proyecto educativo iniciaba su andadura (Gozálvez, 1977: 116). Previo a su secado natural, numerosa mano de obra femenina se encargaba de abrir a mano este producto, actividad que, en el Camp d'Elx, se mecanizó tardíamente, empleando máquinas fabricadas en la zona, alguna de las cuales se muestra en el museo.

Mención aparte merece la palmera datilera, cuyo cultivo se encuentra ampliamente representado en el museo, que conserva y exhibe, entre otros, los enseres tradicionalmente utilizados para subir por los estipes de estas plantas y realizar los diferentes trabajos (recolectar, podar, polinizar, encaperuzar...), propios de cada época del año. La selección, preparación y venta del dátil, así como la elaboración y el trenzado de palma blanca -artesanía secularmente asentada en Elche, relacionada con la festividad del Domingo de Ramos- se muestran en un espacio que reproduce el porche de las casas de campo características de la zona. Al igual que en otras áreas del museo, grandes murales pintados explican estas actividades y el entorno en el que se realizan.

Finalmente, el museo conserva una serie de piezas como recogedores de higos o desgranadoras de maíz, así como enseres relacionados con la caza (de bisbitas y anátidas, entre otras especies), actividades otrora importantes en el área que nos ocupa, con las que se complementaba la dieta de sus vecinos/as (Gozálvez, 1977: 120 y 136).

\subsection{El consumo del producto y los procesos realizados en el ámbito doméstico}

Como se ha mencionado, el Museo Escolar de Puçol abarca en su exposición, en sus líneas de investigación y en su labor de recuperación, la memoria de las formas de vida tanto del medio rural como del medio urbano. Estas eran maneras de vivir muy diferentes, en cuanto a lo laboral, en cuanto a los servicios públicos de los que se disponían y, especialmente, en cuanto a la socialización de los individuos. Pero algo tenían en común: la escasez de recursos, las estrecheces diarias y el esfuerzo ímprobo por la supervivencia. 
Es cierto que, en el campo, los aprietos eran menos; si bien el trabajo era muy duro su fruto aseguraba el alimento suficiente para todo el año. En la ciudad, donde se solía trabajar a jornal en la industria alpargatera, se cobraba semanalmente con seguridad, pero había que administrar bien ese jornal, generalmente escaso. A partir de cierta edad era habitual que los/as niños/as abandonaran los estudios para ponerse a trabajar, contribuyendo así a la economía familiar.

En ambos casos, no se disponía ni de luz eléctrica ni de agua corriente, pero llegó un momento en que la ciudad comenzó a disfrutar de estos servicios, que se demoraron durante décadas en el medio rural. Esto nos lleva a un punto importante: la costumbre ancestral de cocinar a la leña subsistió en el campo ilicitano hasta bien entrado el siglo XX, así como disponer de un aljibe de agua de lluvia para beber y guisar.

En el agro ilicitano la casa solía ser una vivienda unifamiliar, en la que la cocina formaba parte de las estancias interiores. En el Museo Escolar de Puçol se recrea una cocina tradicional, cuyo centro era la chimenea u hogar, abierta y de media altura. Sobre ella había una gran repisa, en la que se disponían las ollas de barro y otros enseres propios de este espacio. Delante de la chimenea se colocaba una pequeña mesa baja en la que la familia se sentaba para realizar las comidas, pero también para pasar la sobremesa y calentarse en invierno al calor del fuego. En muchos casos, en la cocina se ubicaba la puerta del horno de leña, si es que estaba adosado a la casa; en otras ocasiones, el horno era una pieza exenta que se encontraba en el exterior de la vivienda (Figura 2).

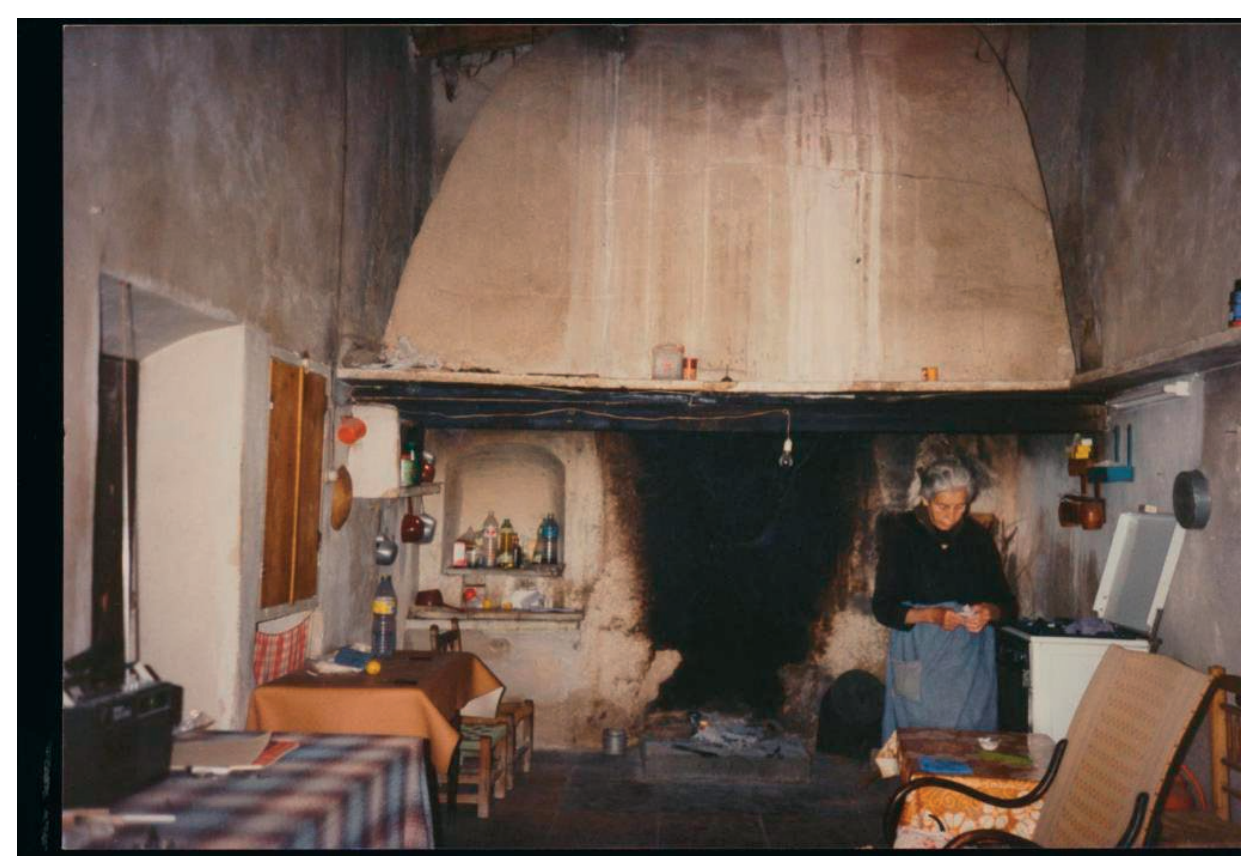

Figura 2. Cocina de una casa tradicional del Camp d'Elx, con la chimenea como elemento central. La cocina de gas y los restos de ceniza en la chimenea ponen de manifiesto la convivencia de ambos métodos de cocción (c..1990). Fuente: Elaboración propia. 
En cuanto a su relación con la alimentación, no eran menos importantes otras estancias. Tan indispensable como la propia cocina era la cambra, una buhardilla en la que se guardaba desde el grano hasta el embutido de la matanza o algunos melones, atados a una caña colgada del techo, de manera trasversal.

Adosada a la cocina se encontraba otra estancia, de pequeñas dimensiones -recreada, asimismo, en el museo-, que actuaba principalmente como despensa. Se trata del pastaor, en el que, además de almacenar alimentos, se amasaba el pan que el ama de casa horneaba semanalmente. En él se ubicaban las orzas con productos de la matanza, pequeñas zafras con aceite de oliva y otros recipientes en los que se preservaban los alimentos, como la fresquera o carnera, una especie de jaula portátil, de malla mosquitera, que colgaba en un lugar fresco para favorecer la conservación de lo que se guardaba en ella. También se ubicaba aquí la artesa, las rasquetas y todo lo necesario para amasar. Una receta típica que se preparaba los días de horneado era la coca a la calda, una torta de masa de pan, con aceite y sal, que requería de poca cocción y que se introducía en el horno a la espera de que este se calentara lo suficiente para meter el pan.

No exclusivamente con la conservación de los alimentos, podemos relacionar las dependencias del hogar campesino, una de ellas de extrema importancia era el corral para criar animales. Y es que esta actividad era primordial en la alimentación familiar, ya que surtía la cocina de carne, aunque fuera en ocasiones contadas. El corral se situaba en la parte trasera de la casa, hacia el norte, y consistía en un espacio más o menos cuadrado, tapiado en sus cuatro lados y en parte sin techar, donde los animales se criaban libremente, pues no les acechaba ningún peligro exterior. Se solía tener gallinas y pollos, algún pavo, patos y ocas, pero también una o dos cabras que surtirían de leche fresca todos los días; y conejillos de indias. Mención aparte merecen los conejos, que no se criaban en libertad por la dificultad que supone atraparlos. En principio, ocupaban grandes agujeros exteriores excavados en el suelo y rodeados de espino, en los que vivían libremente. Cuando se quería atraparlos había que disponer una trampa de lazo unas horas antes y esperar a que uno de los animales quedara prendido. Esta arcaica costumbre decayó hacia el segundo tercio del siglo XX, adoptándose las conejeras como el método más utilizado para su cría.

Tampoco se criaba en el corral a los cerdos, que disponían de su propio espacio en las cochiqueras o marraneras, pequeños recintos independientes en parte techados, separados del resto de dependencias. En cada casa se criaba uno o dos cerdos para el consumo familiar, pero a veces se criaba alguno más para vender. Conocemos, sin embargo, casos de familias con menos recursos que criaban cerdos a medias con otra familia.

La matanza del cerdo era un evento de extrema importancia, pues surtía a la despensa familiar de carne y embutidos para muchos meses. Se realizaba a comienzos del invierno, con el objetivo de que el frío ayudase a curar y conservar los productos. Además del embutido es interesante destacar cómo se conservaba la carne tras la matanza para disponer de ella durante un largo periodo de tiempo: se fileteaba y se iba disponiendo por capas dentro de orzas de barro, vertiendo encima la manteca del cerdo derretida, que actuaba como aislante una vez se solidificaba. Cuando quería extraerse la carne, primero se debía retirar la capa de grasa que la envolvía, la cual se aprovecharía para cocinar o para untar sobre el pan en el almuerzo. 
La comida diaria era de aprovechamiento, sacando el máximo partido a todos los alimentos, pues las sobras de una receta podían ser empleadas como base para nuevos platos. Los huesos de la carne se aprovechaban para hacer un caldo, la cabeza del bonito en salazón se añadía a un guiso, o los sobrantes del puchero o cocido se freían con ajo para hacer ropa vieja.

La lista de ingredientes de un mismo plato podía variar a lo largo del año en base a los productos de temporada. En la época de invierno, la paella de arroz incluía las verduras de estación: alcachofas, guisantes y habas o ajos tiernos. Tras la matanza, a la paella se le podía añadir magra de cerdo, o bien morcillas para acompañar a un arroz con cebolla y patata. En verano, quienes pasaban unos días en las barracas a la orilla del mar, cocinaban una paella de pescado a la que se podían añadir algunas gambas.

La cocina se adaptaba diariamente a la despensa familiar. Predominaban los guisos, que admitían todo tipo de ingredientes, aprovechando la variedad de hortalizas y legumbres. La carne y el pescado frescos eran considerados productos de "lujo que pocas veces se podían permitir. La costum era comprar dos dotzenes de sardines de bota, una cavalla, un bonítol, un bacallar blanc i poques coses mes. Aixó era suficient per a el consum familiar semanal" (sic) (Brotons y Soler, 1986: 72).

Las familias de agricultores, antes de comenzar la jornada de trabajo, preparaban migas o gachamiga, en cualquier caso, un desayuno muy calórico y energético necesario ante el desgaste físico que suponían los trabajos agrícolas. También desayunaban grandes tazones de sopes, una infusión de hierba luisa con azúcar o un tazón de leche de cabra, acompañadas con pan o rosquillas. Para la parada del almuerzo en el campo era común el pan con aceite, que podía ir acompañado de alguna sardina o un trozo de bacalao.

A mediodía, la proximidad entre el hogar y las tierras de labranza permitía a muchos agricultores comer en sus propias casas. De no ser así, la sombra de un árbol era un buen lugar para hacer una pausa para la comida. Las cenas se llevaban a cabo junto a toda la familia en la cocina, al amparo del calor y la luz de la chimenea. No había mucha diferencia entre ambas comidas principales en lo que a variedad de ingredientes se refiere pues, como ya se ha comentado con anterioridad, la escasez de recursos impedía al ama de casa cocinar de forma variada. No obstante, los guisos solían reservarse para la comida principal, pues eran comidas excesivamente calóricas para la cena, en la que se acudía más a los hervidos. Las técnicas de cocción eran de los pocos recursos a los que se recurría para variar dichas recetas.

La gastronomía tradicional del Camp d'Elx incluye entre sus muchas recetas desconocidas un guiso llamado granyons de forment (Brotons y Soler, 1986: 73). Este potaje, denominado en otros rincones como olleta de blat, lleva grano de trigo picado y hervido, junto con verduras de temporada.

Otro de estos platos tradicionales es el conocido como pebreres en l'olla. Se picaba ñora o pimiento rojo, ajo, patatas, judías verdes y cebolla y se añadía a la olla con agua hirviendo, laurel, clavo y aceite de oliva. Una vez casi terminada la cocción, se cascaban unos huevos, se añadían a la olla y se removía. Para terminar, se agregaba un poco de almendra frita picada, un poco de harina y agua.

Aprovechando la cabeza de un bonito en salazón también se preparaban tallarins amb cap de bonito salat. Los tallarines eran caseros. Para su elaboración, sobre una madera o una losa de mármol, se estiraba la masa con la ayuda de un rodillo. Quien no disponía de uno utilizaba 
una botella de cristal, que realizaba la misma función. Cuando la masa estaba lo suficientemente fina, se plegaba varias veces para facilitar el corte. Este se llevaba a cabo con la ayuda de un cuchillo de cocina, dando forma a los tallarines. Finalmente, se estiraban y se dejaban secar encima de la madera. Para este guiso se aprovechaba la cabeza del bonito en salazón, que no se comía normalmente, cociéndola junto con cebolla y tomate fritos y hortalizas. Cuando el caldo estaba listo se añadían los tallarines y se dejaban hervir hasta que estuviesen cocinados.

Las habas más tiernas de la cosecha se cocían, con su vaina incluida, para hacer pantalonets, un hervido de esta legumbre aliñado con aceite, vinagre y sal.

Los días señalados en el calendario, las amas de casa realizaban comidas que requerían mayor elaboración. Los domingos se reservaban para la paella o el arroz con costra. Esta última receta, que ha quedado como plato emblemático en localidades como Aspe, Elche y Orihuela, entre otras poblaciones, se lleva a cabo en un perol de barro. Además de la carne de pollo o conejo, se le añade embutido frito: longaniza blanca, longaniza roja y otros embutidos típicos de esta zona como el blanquet y el botifarrón. Tras la cocción del grano se completa cubriendo este con huevo batido. El perol se puede llevar al horno o puede ser colocado bajo una costrera, que ya se menciona en el Llibre de $\mathrm{Coch}^{5}$. Esta es una especie de tapadera de metal sobre la que se colocan las brasas para que el huevo infle como en un soufflé.

\subsection{La comercialización de los alimentos: mercados, comercios minoristas y restauración}

\subsubsection{El comercio en la ciudad: la tienda de ultramarinos}

Poco se recuerdan ya los comercios de coloniales originales (también conocidos como ultramarinos, colmados, mantequerías, tienditas, abastos, abacerías, abarrotes, desavíos...). Hoy contamos con las grandes superficies de alimentación, con los supermercados y, en los barrios, con esos pequeños negocios regentados habitualmente por inmigrantes. También fue así como nacieron muchas de esas tiendas de comestibles, allá por el siglo XIX, fundadas -en origen- por antiguos habitantes de las colonias españolas, que venían a comercializar los productos procedentes de esas tierras. De ahí el nombre de "ultramarinos", porque vendían productos de ultramar, del otro lado del mar, productos de importación como el café, el chocolate o especias como el azafrán. En 1847, en Elche ya había ocho tiendas de especiería y ultramarinos (Ramos, 1973:191).

La mujer de la ciudad, el ama de casa o la dona de la familia, acudía a estas tiendas a hacer la compra. La costumbre, al entrar en estos negocios de carácter eminentemente familiar, era "pedir la vez", esto es, preguntar el orden de espera o quién era el/la último/a en la cola. La venta a granel, es decir, sin que el producto estuviera previamente empaquetado o envasado, pudiendo pagar la cantidad que la clientela desease, era la forma habitual de comprar. Excepto las conservas -ya cerradas-, los ultramarinos ofrecían a granel casi cualquier producto de consumo, para lo que no podía faltar el papel de estraza: legumbres, embutidos y quesos, dulces, café molido, especias, harina, aceite, vino... Para pesar y tomar medidas de los comestibles, el/a tendero/a hacía uso de una báscula (para el género de mayor tamaño)

\footnotetext{
El Llibre del Coch, de Robert de Nola, es un recetario cuya edición más antigua conservada data de 1520. En este documento - en el que se menciona la costrera - ya aparece la receta de arros en caffola al forn, la que de momento parece ser la primera receta documentada del arroz con costra: "la cassola sobre vn foch de carbo / e damunt met vna cuberta de ferro carregada be de foch per que en tal manera exira de alli com si era stada cuyta al forn [...]".
} 
y una balanza. En el mostrador no podía faltar la bomba de aceite, que extraía la cantidad de producto demandada de un bidón situado en su parte inferior. La clienta llegaba con su propio recipiente vacío, para que se lo rellenasen con la cantidad deseada de aceite.

Dado que se trataba de negocios de "vecindario" y familiares, todos y todas se conocían, siendo tal la confianza que era habitual que el tendero "fiase" a los/as clientes/as, es decir, les permitiera llevarse el género sin pagar, comprometiéndose a hacerlo en otra ocasión.

Además de la compraventa, estas tiendas eran lugares habituales de socialización. Los vecinos y vecinas aprovechaban el momento de la compra para hablar, para contarse las novedades, para la xarradeta diaria.

En la mayoría de ocasiones, estos locales, más que tiendas parecían almacenes, dado que las estanterías estaban repletas de conservas. Los ultramarinos del Museo Escolar de Puçol recrean esta sensación: latas de todo tipo, envases y cajas se colocan en las lejas, que llegan hasta el mismo techo. Una recreación en la que se exponen muchos de los productos y marcas más comercializados.

“Con el paso del tiempo y ante la necesidad de diferenciación en un mercado cada vez más competitivo, fueron apareciendo las distintas marcas con dibujos y colores" (Abad, Beltrá, Lucas y Ortega, 1999: 88 y 89), leemos en Los inicios de la modernización en Alicante, 1882-1914 sobre el azafrán, hecho que se puede extrapolar a otros productos. La diversidad de marcas, los envases decorados, coloridos y de calidad, como el del pimentón "La Carriola" (cuyo logo se identifica con un caballero sentado en un hermoso carro) o las cajas de membrillo, que eran reutilizadas como costurero o para guardar las fotografías familiares, abundan en esta tiendita.

Las piezas expuestas nos ayudan a apreciar, además, la evolución en el diseño de marcas que actualmente continúan en activo. "Cola-Cao" es una de ellas, una marca que pasó de hacer uso de una imagen esclavista de los agricultores negros del chocolate (cargando, encorvados, los capazos de vainas) a publicitar una escena más dulce, de un hombre y una mujer, agricultores del cacao, con una sonrisa en sus rostros. Expuestas también pueden verse cajas de metal de "Cola-Cao" con la imagen de la madre americana sirviendo el desayuno a sus hijos e hijas. Otros productos coloniales que hicieron uso de la típica imagen de la mujer negra de ultramar son los chocolates "La Paraguaya" o "Buana-cacao". Algunos productos, no obstante, poco han cambiado su visual, como "Norit", que ha continuado haciendo uso del cordero blanco desde entonces, o "La lechera" con su chica holandesa vertiendo leche. También destacan aquellas empresas que, dado que vendían típicos productos españoles, explotaban los estereotipos de la flamenca, la gitana o los toros y toreros, como Manolete.

Especial mención merecen las sardinas "de bota" (la sardina entera, salada y prensada -entre el marco y la puerta, para obtener fácilmente los filetes limpios de piel y escamas-), que se colocaban en la "bota" o caja redonda, en la puerta de los ultramarinos, símbolo de la importancia en la época de los salazones.

\subsubsection{El bar/café}

Otro lugar de socialización por excelencia, punto de encuentro habitual para la sociedad, era el bar, pero solo para los hombres. El bar -café o taberna- presentaba, de facto, ciertas limitaciones para las mujeres solas, quienes, habitualmente, solo entraban acompañadas de un varón, de su 
marido, principalmente. Era el lugar de reunión de obreros, labradores y comerciantes, quienes pasaban horas de tertulia, tomando un café o una copa, fumando -algunos escriben sobre el ambiente tan saturado que había-, jugando o escuchando música; incluso, en ocasiones, las charlas daban paso al cierre de negocios.

En el museo se expone el Café/Bar Comercio, que se ubicaba en la Plaça de Baix de Elche, con una gran colección de botellas resultado de las constantes donaciones recibidas. El vino, el anís o "paloma" (3 - 4/5 partes de agua y 1 - 2/5 partes de anís, tomado con el aperitivo), el moscatel y los licores como el coñac y el de café eran, en principio, las bebidas más consumidas (la cerveza se impone como el producto estrella más adelante, avanzado el siglo XX). Muchas de las botellas expuestas están estampadas con imágenes características de la ciudad, la Dama de Elche y las palmeras, principalmente. Algunas proceden de las antiguas fábricas de bebidas ilicitanas, como Vda. de J. Pérez Sánchez, Salas, Vda. de Mariano Pérez Sánchez, sifón higiénico "La Ideal", Productos Fayos -sifones-, Anisete "Che" (de José Vicente Ibarra), Anís Sys (de Salas y Sirvent) o Anís País ${ }^{6}$ (Figura 3).

La higiene y la limpieza en estos negocios, así como en otros muchos -dada la falta de educación sanitaria-, era pobre, su regulación legal llegará más tarde, con el cambio de siglo. Vicente Villalobos, propietario del Bar Villalobos, en el centro de Elche (en activo desde 1901 -primero, como "Casa Barceló"- hasta 2020), relataba en una entrevista (inédita) cómo su abuelo y su padre, propietarios originales del local, preparaban sus famosos bocadillos de atún con un tenedor y sus dedos desnudos.

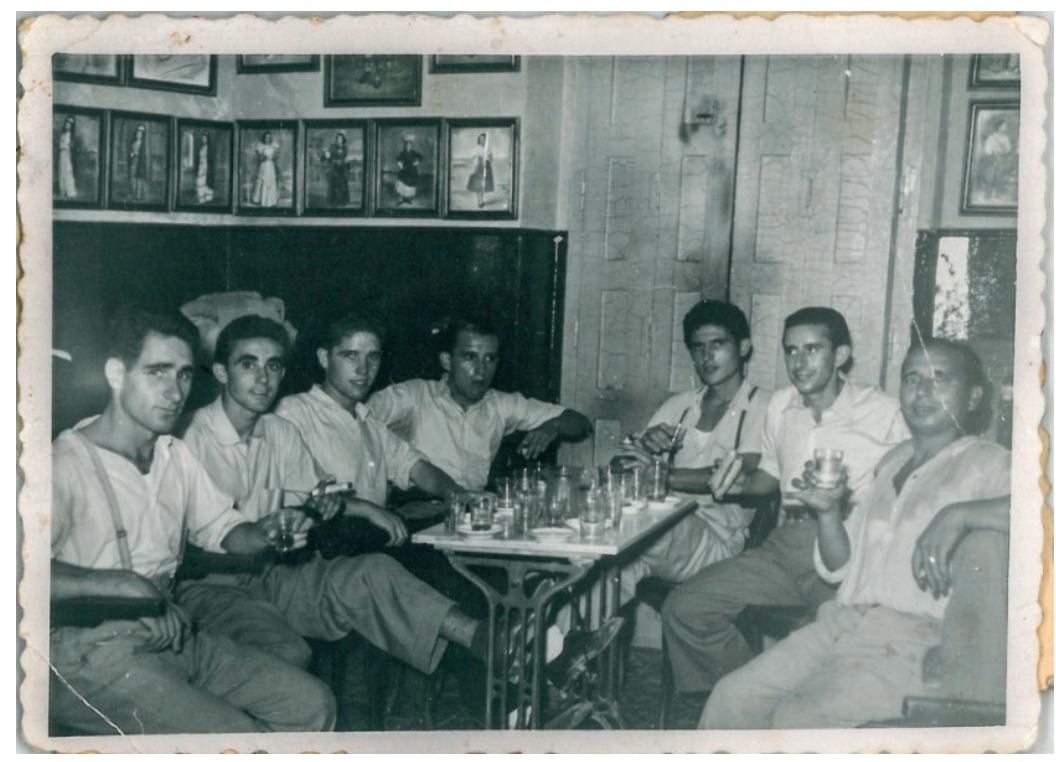

Figura 3. Miembros de la Coral Ilicitana (c. mediados del siglo XX). (Donante: José Juan Alicante Sánchez).

\footnotetext{
${ }^{6}$ El Setiet. Boletín Informativo del Museo Escolar Agrícola de Puçol, nº 18, 2007, p.69.
} 
Los estereotipos, tanto por nacionalidad como por género, vuelven a repetirse en estos locales, que decoraban sus paredes con carteles publicitarios de bebidas o calendarios, protagonizados en gran parte por mujeres exuberantes.

\subsubsection{El carrito de los helados o "chambilero"}

Otro elemento relacionado con los hábitos alimentarios expuesto en el museo es el carrito de los helados. Conocido popularmente como "chambilero", este negocio ambulante vendía por las calles, principalmente a los niños y niñas, polos, mambos, cortes, horchata, cebada, limón y "chambis" o "xambis" (de ahí su nombre). El "xambi" consistía en dos pastas de barquillo o galleta entre los que se colocaba el mantecado, confeccionado con un artilugio de metal, tipo cajetín, del tamaño de la galleta que, al deslizarlo, permitía hacer el corte de mantecado más o menos grueso. Este helado fue inventado e industrializado por los americanos, que lo llamaron "sándwich". Dada la afluencia del turismo americano a nuestro país -especialmente en el Levante- y, por tanto, la demanda de "sándwiches", los heladeros lo incorporaron en sus carritos, que, con el paso del tiempo, posiblemente por una deformación fonética, derivó a la palabra "chambi" (Tristán, 2020).

Los vasos en los que repartían bebidas, como limonada, eran de cristal, puesto que el plástico aún no existía. Los niños y las niñas se la bebían cerca del carrito, pues luego había que devolver el vaso para que el "chambilero" lo fregase. Además de estas bebidas veraniegas, en algunos carritos también se vendían botellines de gaseosa, como el puesto ambulante de Vicente Salvador, que solía ubicarse en la puerta del campanario de la basílica de Santa María de Elche (Pérez, 1996: 40). El carrito que se muestra en el museo es de Helados Parisol, denominado así porque su antiguo propietario, alojado en París, añoraba el sol de España.

\subsubsection{El mercado}

El día de mercado -el sábado- era la jornada de compra por excelencia y la población de la ciudad aumentaba considerablemente, dado que las familias del campo se desplazaban a la ciudad para abastecerse de comestibles (los "ultramarinos" aún no habían llegado a las afueras). Solía viajar el matrimonio -dejando a los hijos e hijas en casa-, a caballo o en un carretet entoldat, a primera hora de la mañana, para poder regresar a medio día y comer todos y todas juntos/as. La jornada era tan importante para el comercio de la ciudad, que las tiendas de comestibles abrían antes, para atender a la población rural.

En el verano de 1888 se inauguró el nuevo mercado de abastos en Elche, con tres grandes y espaciosos pabellones. El cambio de siglo provocó -entre otras cosas- tanto la regulación de la higiene en los mercados (y en otros ámbitos), como la estabilización del calendario de celebración y la construcción de edificios específicos para tal fin (Ponce, 1999: 195). Por tanto, el mercado deja las calles y las plazas -la Plaza Mayor en el caso de Elche- y se asienta de forma permanente en esta nueva construcción. El nuevo mercado reunía, así, la venta de todos los productos y materiales, puesto que, con anterioridad, los puestos se colocaban en una plaza u otra de la ciudad, según lo que vendían: las frutas y verduras en la Plaza de la Fruta, el esparto en la Plazuela de las Barcas, etc. (Ramos, 1973: 191). 
La xarradeta tampoco podía faltar en este momento, igual que pasaba en los ultramarinos. "Lo del mercat, moltes vegades, era sols un pretexte que se buscaba per a poder conversar i reunirse" (Brotons y Soler, 1986: 61). Era costumbre que, mientras la mujer hacía la compra semanal, el marido entrase al bar o café, buscando ese momento de tertulia.

\subsubsection{El comercio en el campo}

Las tiendas de comestibles llegan de forma más tardía al campo, durante la primera mitad del siglo XX, siendo la única opción hasta entonces el desplazarse a la ciudad en día de mercado. Estos negocios unían la venta de conservas y de carne al servicio de bar o café, algo no tan habitual en los ultramarinos de la ciudad. Estas tiendas, de marcado carácter humilde, solían ocupar locales anexos a la vivienda habitual del tendero, es decir, que no eran construcciones independientes, sino que el propietario vivía junto a la tienda, como una habitación más de la casa, a la que se accedía por una entrada paralela a la principal. No obstante, la rutina habitual en el medio rural, antes de que hubiese excedente suficiente para la venta comercial, era intercambiar alimentos con el vecindario.

\subsection{La actividad escolar}

El Proyecto Educativo-Museístico tiene como principal actividad la educación de los/as escolares. Es en Puçol donde el patrimonio y la cultura local se convierten en recursos didácticos y, al mismo tiempo, se ponen en valor. El Museo Escolar, con más de 100.000 ítems, conforma el museo etnográfico de Elche y se erige como una fuente inagotable de conocimiento y un recurso educativo excepcional. El alumnado del colegio recibe una educación adaptada al entorno, donde la experimentación y comprensión de las realidades culturales son un recurso inagotable.

En la actualidad, la escuela se compone de cuatro aulas, en las que estudian alrededor de 55 niños y niñas de 3 a 12 años. Una de las características que hace de este centro una escuela singular es que en la misma clase hay alumnado de distintos niveles y diferentes edades trabajando al mismo tiempo. Esta vertiente propiamente educativa, no sólo se da a través del colegio, sino también a través del museo. Toda la información que se comparte entre los diferentes agentes que intervienen en el Proyecto, ayuda al entendimiento de la cultura tradicional del municipio de Elche y de su entorno.

Gracias a la actividad denominada Guía de Museo, los/as escolares visitantes aprenden de la mano de los/as escolares del colegio, quienes explican la exposición, además de participar en talleres y experiencias con las que se contribuye a la permanencia del conocimiento tradicional.

El entorno en el que nos encontramos propicia el cuidado y la conservación del huerto escolar y el trabajo de la botánica. El alumnado participa activamente en su mantenimiento y está profundamente concienciado de la importancia de cuidar el medio. En el proceso, plantan las semillas, las riegan y recogen la cosecha. Siempre teniendo presente la temporada óptima de verduras y frutas como la coliflor, el brócoli, la romanesco, la ñora, la alcachofa o la vid.

Señas gastronómicas de identidad del Camp d’Elx son los dátiles y las granadas, que no podrían faltar en los jardines de Puçol. De las palmeras no sólo recibimos sus frutos, sino también realizamos actividades como el trenzado de palma blanca o les atxes, una especie de antorchas que se utilizan para iluminar el camino a los Reyes Magos el 5 de enero. 
En Elche contamos con la Denominación de Origen Protegida de la granada mollar, una variedad que el alumnado estudia, conoce y disfruta cada año celebrando el día de la granada y haciendo la recolección de la misma en los frutales que rodean la instalación.

Gracias a la profunda relación multidireccional entre colegio y comunidad, el Proyecto Educativo es depositario de recetas tradicionales de la zona, compartidas a través de la memoria oral de las personas mayores del vecindario. En vías de desaparición estaba el penjoll de mazapán, donde ingredientes como la clara de huevo, el azúcar, el limón y la almendra molida hacen que se consiga obtener una pasta uniforme a la que se le da forma de corazón para, posteriormente, llevarla al horno de leña tradicional, ubicado en el jardín interior. Esta tradición ilicitana era frecuente entre las abuelas como regalo a sus nietos/as en días señalados, especialmente en el santo o el cumpleaños.

La coca a la calda o los "mantecaos" navideños se realizan cada año para que el alumnado conozca las recetas y de esta forma nos aseguremos de que van a ser transmitidas, confiando así en que pasen de generación en generación y no se pierdan.

La estrecha relación que existe entre el colegio, la sociedad y el museo facilita la realización de actividades en las que participa toda la comunidad educativa. Dos ejemplos son el concurso de postres y la elaboración de buñuelos, ambas con recetas tradicionales de la zona (Figura 4 y 5 ).

\section{Resultados}

Desde hace décadas, el Proyecto Educativo-Museístico de Puçol viene desarrollando una activa labor patrimonial en el municipio de Elche y su entorno. Conservar la memoria de la gastronomía

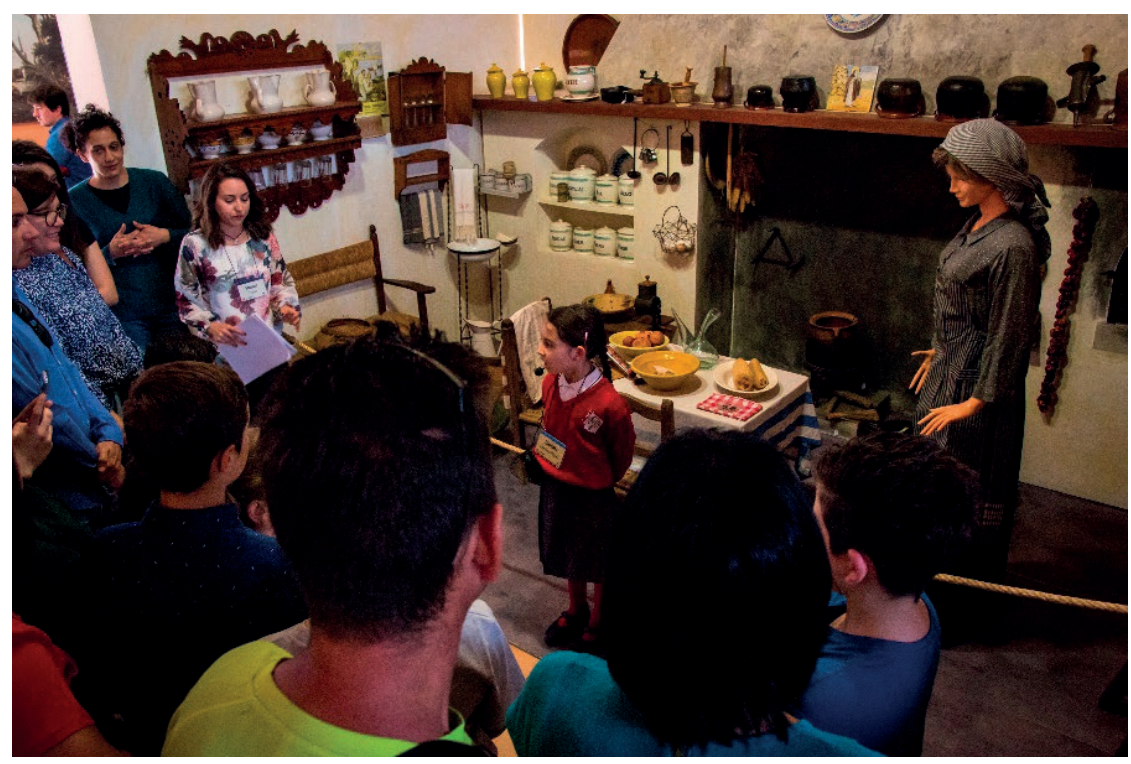

Figura 4. Actividad Guía del Museo en la reproducción de la cocina tradicional de la casa de campo (2018). Fuente: Elaboración propia. 
local siempre fue una de las líneas de investigación desarrolladas por el colegio, cuyos/as alumnos/as recopilan recetas autóctonas, elaboran productos tradicionales, cultivan productos típicos, aprenden ancestrales técnicas agrícolas y otras prácticas domésticas relacionadas con la alimentación y conocen mercados y tiendas antiguas. Todo ello gracias a la activa labor desarrollada por una comunidad educativa volcada en un proyecto que, con el tiempo, trascendió los límites de la pedanía.

El montaje y la guía de exposiciones, la realización de talleres y la edición de publicaciones relacionadas con la alimentación constituyen la consecuente plasmación de una experiencia pedagógica que ha impulsado el conocimiento y el reconocimiento de la cultura local.

\section{Conclusiones}

Tras décadas de existencia, este Proyecto no solo ha sido capaz de asentarse en el seno de la comunidad, sino que ha obtenido importantes reconocimientos nacionales e internacionales, entre otros, el otorgado por la UNESCO en 2009. Su origen, en la pedanía rural, lo convierten en un temprano referente de museos comunitarios creados "de abajo arriba", surgidos de la misma sociedad civil, en unos años de trascendentales cambios experimentados en el país. La recuperación, cuando menos, de la memoria de la sociedad ha convertido al Museo Escolar en un centro de cultura tradicional que conserva, investiga y divulga la historia cotidiana del territorio en el que se asienta. No obstante, lo conseguido en Puçol trasciende sus límites geográficos, pues configura una praxis sostenida en el tiempo, por completo replicable en otros entornos y realidades.

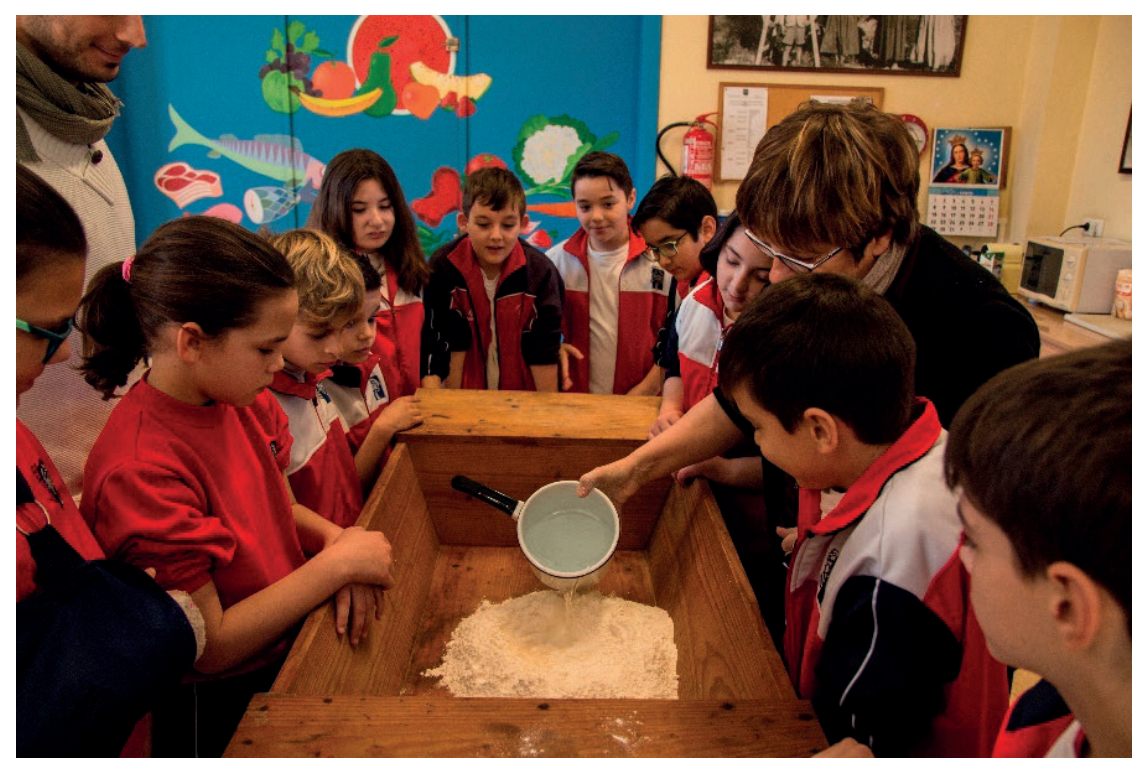

Figura 5. Taller de amasado de pan (2018). Fuente: Elaboración propia. 


\section{Referencias}

ABAD SALA, J., BELTRÁ ZARAGOZA, D., LUCAS GÓMEZ, F. J. y ORTEGA PÉREZ, J. R. (1999). "La vida, el azafrán y el mármol". En: Los inicios de la Modernización en Alicante 1882-1914. Alicante: Caja de Ahorros del Mediterráneo, pp. 88-89.

BROTONS GARCÍA, B. (1985). La agricultura ilicitana, de ayer a hoy. Alicante: Caja de Ahorros Provincial de Alicante.

BROTONS GARCÍA. B. y SOLER VICENTE. A. (1986). S'ha perdut una cultura del Camp d'Elx. Elche: el autor, pp. 73, 72.

GARCÍA FONTANET, F. y PÉREZ ALBERT, J. (s.f.). Proyecto: Centro Escolar del Camp d'Elx para la Integración al Medio, en fotocopia.

GOZÁLVEZ, V. (1977). El Bajo Vinalopó. Geografía Agraria. Valencia: Departamento de Geografía, Universidad de Valencia, pp.115, 120, 129, 137, 116, 136.

GREGORI BERENGUER, J.J. (1998). "Un fresco en la sociedad tradicional valenciana en el último compás del siglo XIX", en Valencianos del 98. Valencia: Diputación de Valencia, Museu d’Etnologia, p.15 y 16.

HERNÁNDEZ HERNÁNDEZ, F. (1994). Manual de museología. Madrid: Síntesis, pp. 201-230.

LACARRA, J., SANCHEZ, X. y JARQUE, F. (1997). Las Observaciones de Cavanilles doscientos años después, vol. IV. Valencia: Bancaja, p. 338.

MARTÍNEZ GARCÍA, R., PICÓ LEDESMA, I, ANIORTE PÉREZ, J., TRISTÁN RICHARTE, M. y SANCHO QUEROL, L. (2019). POEM. Proyecto Educativo-Museístico. Museo Escolar de Puçol. Elche: Proyecto Puçol.

PÉREZ SORIANO, F. (1996). "Los Comercios" en García Fontanet, F. La calle de El Salvador. Elche: Museo Escolar de Puçol, p. 40.

PONCE HERRERO, G. (1999). "La modernización de los servicios” en Los inicios de la Modernización en Alicante 1882-1914. Alicante: Caja de Ahorros del Mediterráneo, p. 195.

RAMOS FOLQUÉS, A. (1973). La industria, el comercio y la agricultura en Elche. Elche: el autor, pp. 185-191.

El Setiet. Boletín Informativo del Museo Escolar Agrícola de Puçol (1998), n 8. Elche: Museo Escolar de Puçol. <www.museopusol.com/media/descargas/23.pdf> [Consulta: 17 de julio de 2021].

El Setiet. Boletín Informativo del Museo Escolar Agrícola de Puçol (2007), n 18. Elche: Museo Escolar de Puçol. p.69. <www.museopusol.com/media/descargas/14.pdf> [Consulta: 17 de julio de 2021].

TRISTÁN RICHARTE, M. (2020). "¡Ya viene el chambilero!". www.museopuçol.com/es/ blog/?cat=5\&id=115\&dat=06\%202020 [Consulta: 17 de julio 2021]. 